\title{
A New Standard of Care: Pembrolizumab in Programmed Death-ligand 1 Positive, Metastatic, Triple-negative Breast Cancer
}

\author{
Kai CC Johnson, ${ }^{1}$ Robert Wesolowski ${ }^{1,2}$ and Margaret E Gatti-Mays ${ }^{1,2}$ \\ 1. Stefanie Spielman Comprehensive Breast Center, Columbus, OH, USA; 2. Pelotonia Institute for Immuno-Oncology, Division of Medical \\ Oncology, The Ohio State University Comprehensive Cancer Center, Columbus, OH, USA
}

$\mathrm{M}$ etastatic triple-negative breast cancer (mTNBC) carries a poor prognosis, with a median survival of 1-2 years. Despite multiple attempts at using immunotherapy in this patient population, it was only in recent years that large-scale clinical trials, studying immune checkpoint inhibitors (ICI) in MTNBC, have emerged with promising data. First came approval from the US Food and Drug Administration (FDA) in 2017 for the use of pembrolizumab in solid tumours found to be either microsatellite instability high or mismatch repair deficient, illuminating the potential role of immunotherapy in select patients with breast cancer. Then in 2019, following the results of the IMpassion130 trial, atezolizumab became the first $\mathrm{ICl}$ approved for use in breast cancer, specifically as combination therapy with nab-paclitaxel for patients with programmed death-ligand 1 (PD-L1)-positive mTNBC. In early 2020, pembrolizumab was approved for use in solid tumours with a high tumour mutational burden, which represents a small population of breast cancer patients. In late 2020, based upon the results of the KEYNOTE-355 trial, the FDA approved pembrolizumab for use in combination with conventional chemotherapy for PD-L1-positive MTNBC, specifically in patients found to have tumours with a combined positive score $\geq 10$. Outside of mTNBC, pembrolizumab has also received FDA approval for use in high-risk, early-stage triple-negative breast cancer (TNBC) as of July 2021, following the regulatory release of KEYNOTE-522 which demonstrated improved outcomes when used in combination with neoadjuvant chemotherapy, followed by adjuvant pembrolizumab monotherapy. This review will focus on the details surrounding these landmark trials and discuss how pembrolizumab has become integrated into the new standard of care for patients with PD-L1-positive MTNBC.

\section{Keywords}

Breast cancer, triple-negative, metastatic breast cancer, immunotherapy, immune checkpoint inhibitor, PD-L1, tumour immunology, pembrolizumab

Disclosures: Kai CC Johnson, Robert Wesolowski and Margaret E Gatti-Mays have no financial or non-financial relationships or activities to declare in relation to this article.

Acknowledgements: The authors would like to thank Kamila Jaroniec for her editing and thoughtful review.

Review process: Double-blind peer review.

Compliance with ethics: This study involves a review of the literature and did not involve any studies with human or animal subjects performed by any of the authors.

Authorship: The named authors meet the International Committee of Medical Journal Editors (ICMJE) criteria for authorship of this manuscript, take responsibility for the integrity of the work as a whole, and have given final approval for the version to be published.

Access: This article is freely accessible at

touchONCOLOGY.com. (C) Touch Medical Media 2021

Received: 27 April 2021

Accepted: 6 July 2021

Published online: 10 November 2021

Citation:touchREVIEWS in Oncology \& Haematology. 2021;17(2):60-7

Corresponding author: Margaret E Gatti-Mays,

The Ohio State University, 1800 Cannon Drive,

1300A Lincoln Tower, Columbus, OH, USA,

43210. E: margaret.gatti-mays@osumc.edu

Support: No funding was received in

the publication of this article.
Cumulatively, TNBC accounts for $35-40 \%$ of breast cancer deaths in the United States, despite only comprising 10-15\% of total breast cancer cases diagnosed. ' Even before the use of antiestrogen therapies became widespread, hormone receptor-positive breast cancer (HR+BC) provided a far more favourable risk of recurrence and overall prognosis compared with TNBC. ${ }^{2,3}$ Once metastatic, TNBC historically carries a median overall survival (mOS) of roughly 18-25 months with the use of conventional cytotoxic chemotherapy. ${ }^{4,5}$ In light of this, breast cancer researchers, industry leaders and drug regulators, including the FDA, have focused on ways to streamline therapies and accelerate drug approvals, both for early- and late-stage TNBC. ${ }^{6.7}$ However, for the purpose of this review, we will be focusing primarily on the use of pembrolizumab in metastatic triple-negative breast cancer.

\section{Programmed death-1, programmed death-ligand 1 and cytotoxic T-lymphocyte antigen 4 function}

Programmed death-1 (PD-1) and cytotoxic T-lymphocyte antigen 4 (CTLA4) are inhibitory molecules located on the surface of circulating immune cells, including cytotoxic and helper T-cells., ${ }^{8,9}$ PD-1 binds to programmed death-ligand 1 (PD-L1) and 2 (PD-L2), whereas CTLA4 binds to ligands B7-1 and B7-2. Once bound to their appropriate ligands, these surface proteins are responsible for a signal cascade that ultimately leads to immunosuppression due to decreased immune-cell activation. Under normal physiology, PD-L1 is expressed by a variety of cell types, including those in the thymus, cornea, testis and placenta, to prevent autoimmune responses and to allow for the creation of immune-privileged regions. ${ }^{10,11}$ The expression of PD-L1 by malignant cells and surrounding tumour-infiltrating immune cells plays a similar role in that it enables cancer cells to elude the immune system in order to avoid destruction. ${ }^{12,13}$ PD-L2 is expressed predominantly on professional antigen-presenting cells, including macrophages and dendritic cells. ${ }^{14} \mathrm{PD}-\mathrm{L} 2$ is also expressed in the respiratory and gastrointestinal tracts, as well as in a wide variety of malignancies, including TNBC.10

Researchers have been able to overcome tumour immune evasion by creating ICls, including anti-CTLA4 (ipilimumab), anti-PD-1 (pembrolizumab, nivolumab, cemiplimab, dostarlimab) and anti-PD-L1 (atezolizumab, durvalumab, avelumab) antibodies. ${ }^{15-17}$ These ICIs restore the immune system's capability to induce apoptosis and release cytotoxic factors within the tumour. Additional ICls remain on the horizon and are being fast tracked at a rapid pace. 


\section{Pembrolizumab}

Pembrolizumab (previously MK-3475) is a human immunoglobulin G (IgG)4 kappa monoclonal antibody antagonist of PD-1. Manufactured by Merck \& Co., the marketed version of the drug, Keytruda ${ }^{\circledast}$, has a half-life of approximately 23 days. ${ }^{18}$ Pembrolizumab received breakthrough designation in 2013 and accelerated FDA approval in 2014 following the success of the KEYNOTE-001 trial in ipilimumab-refractory advanced melanoma. ${ }^{19}$ As of July 2021, pembrolizumab has 29 FDAapproved indications, making it acceptable for use as monotherapy or in combination with other agents (Table 1). ${ }^{20}$ More broadly, pembrolizumab has also received tissue-agnostic approval for use in solid tumours found to be microsatellite instability high (MSI-H; defined as $\geq 30 \%$ mutations), mismatch repair deficient (dMMR), or in solid tumours with a high tumour mutational burden (TMB-H; defined as $\geq 10$ mutations/megabase). ${ }^{21,22}$ Even within the field of breast cancer, the indications for pembrolizumab continue to expand quickly. In July 2021, the US FDA granted accelerated approval of pembrolizumab for use in high-risk, early-stage TNBC when used in combination with neoadjuvant chemotherapy, followed by administration as adjuvant monotherapy based on the results of KEYNOTE-522. ${ }^{23}$ Further discussion of the use of pembrolizumab in the neoadjuvant setting is beyond the scope of this review. The timeline of pembrolizumab approval for use in breast cancer is illustrated in Figure 1.

\section{High microsatellite instability and high tumour mutational burden}

Certain features in solid tumour malignancies have been linked to increased $\mathrm{ICl}$ responsiveness, starting with tumour mutational burden (TMB). The increasing presence of somatic mutations in malignant cells leads to increased expression of neoantigens on their surface via major histocompatibility complex class I (MHC-1) proteins, resulting in higher rates of lymphocyte detection and activation. ${ }^{24}$ Another feature is microsatellite instability (MSI). Microsatellites are short tandem repeats of DNA found scattered across the genome that are prone to replication errors due to slippage by DNA polymerase, which in turn leads to the addition and/or removal of bases, causing the formation of mismatched DNA strands. These are typically repaired by mismatch repair (MMR) proteins, which include MLH1, MSH2, MSH6 and PMS2, but tumours deficient in any one of these proteins are unable to correct these errors, leading to MSI and the accumulation of somatic mutations with downstream expression of neoantigens. ${ }^{25}$ Large-scale clinical trials have since validated these findings, and demonstrated that higher response rates to pembrolizumab are observed in solid malignancies that are either TMB-H or MSI-H. ${ }^{21,22,26,27}$

Data pooled from five key, single-arm, multi-cohort studies (KEYNOTE-158, ${ }^{21}$ KEYNOTE-016, ${ }^{27}$ KEYNOTE-164, ${ }^{28}$ KEYNOTE-012 ${ }^{29}$ and KEYNOTE-02830) were used by the FDA in 2017 to determine pembrolizumab efficacy in patients found to have MSI-H or dMMR tumours. 18,21 Of the 149 patients found to have MSI-H or dMMR tumours at the time of review, $98.0 \%$ of them had metastatic disease, with a slim minority (1.3\%) involving primary breast carcinomas. Collectively, the objective response rate (ORR) was $39.6 \%$ with a complete response (CR) rate of $7.4 \%$. When examining the non-colorectal carcinoma category, ORR improved to $46.0 \%$.

The 10 cohorts (A-J) of KEYNOTE-158 were also examined to determine pembrolizumab efficacy in patients with TMB-H non-colorectal tumours. ${ }^{18,22}$ Similarly to the MSI-H studies mentioned above, these cohorts were designed as phase $\|$, single-arm trials involving pembrolizumab therapy which was continued until disease progression or an unacceptable toxicity was observed. Of the 1,050 patients enrolled, only 102 (13.0\%) had confirmed TMB-H tumours. The majority of patients had small-cell lung cancer (33.0\%), cervical cancer (16.0\%), vulvar cancer (15\%) and anal cancer (14.0\%). No breast cancer patients met TMB-H criteria. The ORR for TMB-H patients was $29.0 \%$ (versus 6.0\% for non-TMB-H matched controls). When excluding those with concurrent MSI-H and TMB-H tumours (21.0\% of the TMB-H patients), ORR was $28.0 \%$.

Recent large-scale retrospective analyses have estimated MSI-H prevalence to be roughly $0.4 \%$ in TNBC, $0.2 \%$ in $\mathrm{HR}+\mathrm{BC}$ and $0.1 \%$ in human epidermal growth factor receptor 2-positive breast cancer $(\mathrm{HER} 2+\mathrm{BC})$, whereas TMB-H prevalence was estimated at $9 \%$ in TNBC, $8.0 \%$ in $\mathrm{HR}+\mathrm{BC}$ and $12.0 \%$ in HER2+BC. ${ }^{31}$ Additionally, metastatic tumours confer higher rates of TMB-H prevalence compared with localized tumours (8.4\% versus $2.9 \%$ ), as do invasive lobular carcinomas over invasive ductal carcinomas (17.0\% versus $7.8 \%$ ). ${ }^{32}$ When comparing outcomes in patients found to be TMB-H, there is no clear correlation between increasing TMB levels and progression-free survival (PFS) with the use of pembrolizumab monotherapy. The recently reported TAPUR study demonstrated some signs of clinical efficacy with pembrolizumab monotherapy in TMB-H breast tumours, with a disease control rate of $37.0 \%$ and an ORR of $21.0 \%{ }^{33}$ Important to note is that responses were seen in TMB-H breast tumours irrespective of hormone receptor status.

\section{Programmed death-ligand 1 expression}

Immunohistochemistry $(\mathrm{IHC})$ is used to quantify the cumulative surface expression of PD-L1 on both malignant cells and immune cells. For breast cancer specifically, the two most commonly used assays are Ventana SP142 (Roche, Basel, Switzerland) and Dako 22C3 (Agilent Technologies, Santa Clara, CA, USA). ${ }^{34,35}$ Ventana SP142 is the companion assay used for atezolizumab studies. It reports the percentage of PD-L1 expression seen on tumour cells and immune cells, with a positivity cut-off set at immune cells $\geq 1.0 \%{ }^{36}$ In contrast, Dako $22 \mathrm{C} 3$ is the companion assay used for pembrolizumab studies. It reports the cumulative expression of PD-L1 on tumour cells and immune cells to calculate a combined positive score (CPS) with a positivity cut off of $\geq 10$ for pembrolizumab approval in TNBC. ${ }^{37-39}$ These assays are not interchangeable and have different cut-offs depending on the cancer type. The overall rate of PD$L 1$ positivity in TNBC ranges from $20-60 \%$ depending on the assays and methods used..$^{40-42}$ Lower expression is seen in distant lesions involving the liver, bones and skin, whereas higher expression is seen in metastatic deposits in the brain, lungs and lymph nodes. ${ }^{43,44}$ High PD-L1 expression is also seen when tumours carry activating mutations in the oncogene phosphatidylinositol-4,5-bisphosphate 3-kinase catalytic subunit alpha (PIK3CA), as well as in those with deleterious mutations involving the tumour suppressor gene phosphatase and tensin homologue (PTEN). ${ }^{45}$ Interestingly, these mutations confer resistance to checkpoint inhibitors across various solid malignancies, though concurrent use of PIK3CA inhibitors may sensitize tumour cells to immunotherapy. ${ }^{46}$ Using conventional chemotherapy, particularly paclitaxel, has also been shown to increase both mRNA and surface protein expression of PD-L1 in TNBC. ${ }^{47,48}$

\section{Pembrolizumab monotherapy \\ KEYNOTE-012}

KEYNOTE-012 was a phase $\mathrm{Ib}$ trial investigating the treatment activity and overall safety of pembrolizumab monotherapy in 27 patients with advanced PD-L1-positive TNBC. ${ }^{29,49}$ Pembrolizumab monotherapy produced an ORR of $18.5 \%$, median-PFS (MPFS) of 1.9 months and mOS of 10.2 months. Given that most patients were heavily pre-treated (25\% had received $\geq 5$ prior lines of therapy), these efficacy results were an 
Table 1: Summary of the US Food and Drug Administration-approved indications for pembrolizumab, both as monotherapy and as combination therapy

\begin{tabular}{|c|c|c|c|c|c|}
\hline Disease & Therapy & Indication & $\begin{array}{l}\text { Trial on which } \\
\text { approval was based }\end{array}$ & Trial design & $\begin{array}{l}\text { NCCN category } \\
\text { of evidence }\end{array}$ \\
\hline Adult $\mathrm{CHL}$ & Monotherapy & $\begin{array}{l}\text { Second line after multiagent } \\
\text { therapy }\end{array}$ & KEYNOTE-204 (NCT02684292) & $\begin{array}{l}\text { Pembrolizumab versus } \\
\text { brentuximab vedotin }\end{array}$ & $2 \mathrm{~A}$ \\
\hline Paediatric $\mathrm{CHL}$ & Monotherapy & $\begin{array}{l}\text { Second line after multiagent } \\
\text { therapy or third line for } \\
\text { relapsed disease }\end{array}$ & KEYNOTE-204 (NCT02684292) & $\begin{array}{l}\text { Pembrolizumab versus } \\
\text { brentuximab vedotin }\end{array}$ & $2 \mathrm{~A}$ \\
\hline $\begin{array}{l}\text { Adult and paediatric } \\
\mathrm{PMBCL}\end{array}$ & Monotherapy & $\begin{array}{l}\text { Second line after multiagent } \\
\text { therapy or third line for } \\
\text { relapsed disease }\end{array}$ & KEYNOTE-170 (NCT02576990) & Single arm pembrolizumab & $2 \mathrm{~A}$ \\
\hline Melanoma & Monotherapy & $\begin{array}{l}\text { Adjuvant therapy if lymph } \\
\text { node positive after complete } \\
\text { resection }\end{array}$ & KEYNOTE-054 (NCT02362594) & Pembrolizumab versus placebo & 1 \\
\hline Melanoma & Monotherapy & $\begin{array}{l}\text { First line metastatic or } \\
\text { unresectable }\end{array}$ & KEYNOTE-006 (NCT01866319) & Pembrolizumab versus ipilimumab & $2 \mathrm{~A}$ \\
\hline $\begin{array}{l}\text { Adult and paediatric } \\
\text { Merkel }\end{array}$ & Monotherapy & $\begin{array}{l}\text { First line metastatic or } \\
\text { recurrent locally advanced } \\
\text { disease }\end{array}$ & KEYNOTE-017 (NCT02267603) & Single arm pembrolizumab & $2 \mathrm{~A}$ \\
\hline cSqCC & Monotherapy & $\begin{array}{l}\text { First line recurrent or } \\
\text { metastatic disease that is not } \\
\text { curable by surgery or radiation }\end{array}$ & KEYNOTE-629 (NCT03284424) & Single arm pembrolizumab & $2 \mathrm{~A}$ \\
\hline NSCLC & $\begin{array}{l}\text { Combination } \\
\text { (pemetrexed } \\
\text { \& platinum } \\
\text { chemotherapy) }\end{array}$ & $\begin{array}{l}\text { First line metastatic } \\
\text { non-squamous* }\end{array}$ & KEYNOTE-189 (NCT02578680) & $\begin{array}{l}\text { Pembrolizumab versus placebo in } \\
\text { combination with pemetrexed \& } \\
\text { platinum chemotherapy }\end{array}$ & 1 \\
\hline NSCLC & $\begin{array}{l}\text { Combination } \\
\text { (carboplatin \& } \\
\text { paclitaxel or } \\
\text { nab-paclitaxel) }\end{array}$ & First line metastatic squamous & KEYNOTE-407 (NCT02775435) & $\begin{array}{l}\text { Pembrolizumab versus placebo in } \\
\text { combination with carboplatin and } \\
\text { either paclitaxel or nab-paclitaxel }\end{array}$ & 1 \\
\hline NSCLC & Monotherapy & $\begin{array}{l}\text { First line advanced if PD-L1 } \\
\text { TPS } \geq 1 \%\end{array}$ & KEYNOTE-042 (NCT02220894) & Single arm pembrolizumab & $\begin{array}{l}2 B \text { if } T P S \geq 1 \% \\
1 \text { if } \text { TPS } \geq 50 \%\end{array}$ \\
\hline NSCLC & Monotherapy & $\begin{array}{l}\text { Second line metastatic if PD-L1 } \\
\text { TPS } \geq 1 \%\end{array}$ & KEYNOTE-010 (NCT01905657) & Pembrolizumab versus docetaxel & 1 \\
\hline HNSCC & $\begin{array}{l}\text { Combination } \\
\text { (fluorouracil \& } \\
\text { platinum agent) }\end{array}$ & $\begin{array}{l}\text { First line metastatic or } \\
\text { unresectable recurrent }\end{array}$ & KEYNOTE-048 (NCT02358031) & $\begin{array}{l}\text { Pembrolizumab versus } \\
\text { combination versus } \\
\text { chemotherapy alone }\end{array}$ & $2 \mathrm{~A}$ \\
\hline HNSCC & Monotherapy & $\begin{array}{l}\text { First line metastatic or } \\
\text { unresectable recurrent if PD-L1 } \\
\mathrm{CPS} \geq 1 \%\end{array}$ & KEYNOTE-048 (NCT02358031) & $\begin{array}{l}\text { Pembrolizumab versus } \\
\text { combination versus } \\
\text { chemotherapy alone }\end{array}$ & $2 \mathrm{~A}$ \\
\hline HNSCC & Monotherapy & $\begin{array}{l}\text { Second line metastatic or } \\
\text { recurrent after platinum } \\
\text { chemotherapy }\end{array}$ & KEYNOTE-012 (NCT01848834) & Single arm pembrolizumab & $\begin{array}{l}1 \text { if non- } \\
\text { nasopharyngeal } \\
\text { 2B if } \\
\text { nasopharyngeal } \\
\text { and PD-L1 } \\
\text { positive }\end{array}$ \\
\hline Oesophageal & Monotherapy & Second line if PD-L1 CPS $\geq 10$ & $\begin{array}{l}\text { KEYNOTE-181 (NCT02564263) and } \\
\text { KEYNOTE-180 (NCT02559687) }\end{array}$ & Both single arm pembrolizumab & $2 \mathrm{~A}$ \\
\hline Oesophageal & $\begin{array}{l}\text { Combination } \\
\text { (fluorouracil \& } \\
\text { platinum agent) }\end{array}$ & $\begin{array}{l}\text { First line in metastatic or } \\
\text { unresectable locally advanced } \\
\text { disease, including GEJ }\end{array}$ & KEYNOTE-590 (NCT03189719) & $\begin{array}{l}\text { Pembrolizumab + chemotherapy } \\
\text { versus chemotherapy alone }\end{array}$ & $\begin{array}{l}1 \text { if } C P S \geq 10 \\
+ \text { cisplatin } \\
2 A \text { if } C P S \geq 10 \\
+ \text { oxaliplatin } \\
2 B \text { if CPS } 1-9\end{array}$ \\
\hline Gastric & Monotherapy & $\begin{array}{l}\text { Third line after fluoropyrimidine } \\
\text { and platinum therapy as well } \\
\text { as HER2-targeted therapy if } \\
\text { applicable, if PD-L1 CPS } \geq 1\end{array}$ & KEYNOTE-059 (NCT02335411) & Single arm pembrolizumab & $2 \mathrm{~A}$ \\
\hline
\end{tabular}


Table 1: Continued

\begin{tabular}{|c|c|c|c|c|c|}
\hline Disease & Therapy & Indication & $\begin{array}{l}\text { Trial on which } \\
\text { approval was based }\end{array}$ & Trial design & $\begin{array}{l}\text { NCCN category } \\
\text { of evidence }\end{array}$ \\
\hline Gastric & $\begin{array}{l}\text { Combination } \\
\text { (trastuzumab, } \\
\text { fluoropyrimidine, and } \\
\text { platinum agent) }\end{array}$ & $\begin{array}{l}\text { First line in HER2+ metastatic } \\
\text { or unresectable locally } \\
\text { advanced gastric or GEJ } \\
\text { adenocarcinoma }\end{array}$ & $\begin{array}{l}\text { KEYNOTE-811 } \\
\text { (NCT03615326) }\end{array}$ & $\begin{array}{l}\text { Pembrolizumab + chemotherapy } \\
\text { versus chemotherapy alone }\end{array}$ & $2 \mathrm{~A}$ \\
\hline $\mathrm{HCC}$ & Monotherapy & Second line after sorafenib & KEYNOTE-224 (NCT02702414) & Single arm pembrolizumab & $2 \mathrm{~B}$ \\
\hline $\mathrm{RCC}$ & Combination (axitinib) & First line advanced & KEYNOTE-426 (NCT02853331) & $\begin{array}{l}\text { Pembrolizumab + axitinib } \\
\text { versus sunitinib }\end{array}$ & $\begin{array}{l}1 \text { if intermediate } \\
\text { or poor risk } \\
2 \mathrm{~A} \text { if favourable } \\
\text { risk }\end{array}$ \\
\hline Urothelial & Monotherapy & $\begin{array}{l}\text { Second line after platinum } \\
\text { chemotherapy }\end{array}$ & $\begin{array}{l}\text { KEYNOTE-045 } \\
\text { (NCT02256436) }\end{array}$ & $\begin{array}{l}\text { Pembrolizumab versus physician's } \\
\text { choice chemotherapy }\end{array}$ & 1 \\
\hline Urothelial & Monotherapy & $\begin{array}{l}\text { First line if platinum ineligible } \\
\text { and PD-L1 CPS } \geq 10\end{array}$ & $\begin{array}{l}\text { KEYNOTE-052 } \\
\text { (NCT02335424) }\end{array}$ & Single arm pembrolizumab & $2 \mathrm{~A}$ \\
\hline Urothelial & Monotherapy & $\begin{array}{l}\text { BCG-unresponsive high-risk } \\
\text { NMIBC with CIS if ineligible } \\
\text { for or chose not to pursue } \\
\text { cystectomy }\end{array}$ & KEYNOTE-057 (NCT02625961) & Single arm pembrolizumab & $2 \mathrm{~A}$ \\
\hline Endometrial & $\begin{array}{l}\text { Combination } \\
\text { (lenvatinib) }\end{array}$ & $\begin{array}{l}\text { Second line after systemic } \\
\text { therapy and is not candidate } \\
\text { for curative surgery or radiation }\end{array}$ & KEYNOTE-146 (NCT02501096) & $\begin{array}{l}\text { Single arm combination } \\
\text { pembrolizumab + lenvatinib }\end{array}$ & $2 \mathrm{~A}$ \\
\hline Cervical & Monotherapy & Second line if PD-L1 CPS $\geq 1$ & KEYNOTE-158 (NCT02628067) & Single arm pembrolizumab & $2 \mathrm{~A}$ \\
\hline Breast & $\begin{array}{l}\text { Combination } \\
\text { (paclitaxel, } \\
\text { nab-paclitaxel } \\
\text { or combined } \\
\text { gemcitabine + } \\
\text { carboplatin) }\end{array}$ & $\begin{array}{l}\text { First line for metastatic or } \\
\text { locally recurrent unresectable } \\
\text { TNBC that is PD-L1 CPS } \geq 10\end{array}$ & KEYNOTE-355 (NCT02819518) & $\begin{array}{l}\text { Pembrolizumab + chemotherapy } \\
\text { versus } \\
\text { chemotherapy alone }\end{array}$ & 1 \\
\hline Breast & $\begin{array}{l}\text { Combination } \\
\text { (paclitaxel + } \\
\text { carboplatin) }\end{array}$ & $\begin{array}{l}\text { First line for high risk, early } \\
\text { stage TNBC that is PD-L1 CPS } \\
\geq 10\end{array}$ & $\begin{array}{l}\text { KEYNOTE-522 } \\
\text { (NCT03036488) }\end{array}$ & $\begin{array}{l}\text { Pembrolizumab + chemotherapy } \\
\text { versus chemotherapy alone }\end{array}$ & N/A \\
\hline Solid tumours & Monotherapy & $\begin{array}{l}\text { First line for TMB-H ( } \geq 10 \text { mut/ } \\
\text { Mb) metastatic or previously } \\
\text { treated unresectable disease }\end{array}$ & $\begin{array}{l}\text { KEYNOTE-012 (NCT01848834) } \\
\text { KEYNOTE-016 (NCT01876511) } \\
\text { KEYNOTE-028 (NCT02054806) } \\
\text { KEYNOTE-158 (NCT02628067) } \\
\text { KEYNOTE-164 (NCT02460198) }\end{array}$ & Single arm pembrolizumab & $2 \mathrm{~A}$ \\
\hline Solid tumours & Monotherapy & $\begin{array}{l}\text { First line for MSI-H or dMMR } \\
\text { metastatic or unresectable } \\
\text { disease }\end{array}$ & $\begin{array}{l}\text { KEYNOTE-158 (NCT02628067) } \\
\text { KEYNOTE-177 (NCT02563002) }\end{array}$ & Single arm pembrolizumab & $2 \mathrm{~A}$ \\
\hline
\end{tabular}

BCG = Bacille Calmette-Guérin; $C H L=$ classic Hodgkin's lymphoma; CIS = carcinoma in situ; $C P S=$ combined positive score; cSqCC = cutaneous squamous cell carcinoma; $d M M R=$ deficient mismatch repair; GEJ = gastroesophageal junction; HCC = hepatocellular carcinoma; HER2+ = human epidermal growth factor receptor $2 ;$ HNSCC = head and neck squamous cell carcinoma; $\mathrm{MSI}-\mathrm{H}=$ microsatellite instability high; mut/Mb = mutations per megabase; NCCN = National Comprehensive Cancer Network; $N M I B C=$ non-muscle invasive bladder cancer; NSCLC = non-small cell lung carcinoma; $P D-L 1=$ programmed death-ligand 1; $P M B C L=$ primary mediastinal B-Cell lymphoma; $R C C=$ renal clear cell carcinoma; TMB-H = tumour mutational burden high; TNBC = triple-negative breast cancer; TPS = tumour proportion SCore.

improvement compared with historic single-agent chemotherapy. In light of its promising anti-tumour activity and tolerable safety profile, further large-scale trials were conducted to better assess efficacy outcomes.

\section{KEYNOTE-086}

KEYNOTE-086 was a phase II trial with two cohorts. Cohort A evaluated pembrolizumab in patients who progressed on $\geq 1$ prior metastatic therapy, and cohort B evaluated treatment-naïve patients with PD-L1positive, mTNBC. ${ }^{50,51}$ The results of cohort A were released first with a reported ORR of merely 5.3\% that was unaffected by PD-L1 expression ( $5.7 \%$ if PD-L1 positive and $4.7 \%$ if PD-L1 negative), along with an MPFS of 2.0 months and mOS of 9.0 months. However, for cohort B, the results were more promising, with an ORR of $21.4 \%$, mPFS of 2.1 months, and mos of 18.0 months. When compared with standard-of-care, single- agent chemotherapy, the results were positive and ultimately led to a head-to-head comparison trial, KEYNOTE-119.

\section{KEYNOTE-119}

The interim results of KEYNOTE-119 were released at the 2019 European Society of Medical Oncology (ESMO) Congress. ${ }^{52}$ KEYNOTE-119 was a phase III trial performed to determine if pembrolizumab monotherapy was superior to conventional chemotherapy (physician's choice) in 622 patients with treatment-refractory mTNBC. For chemotherapy options, however, investigators' choices were limited to either capecitabine, eribulin, gemcitabine or vinorelbine. The primary outcome of overall survival was stratified to evaluate patients with a CPS $\geq 10, C P S \geq 1$ and those in the intention-to-treat (ITT) population. After a median follow-up of 9.9 months in the experimental arm and 10.9 months 
Figure 1: Timeline of pembrolizumab approval for use in breast cancer

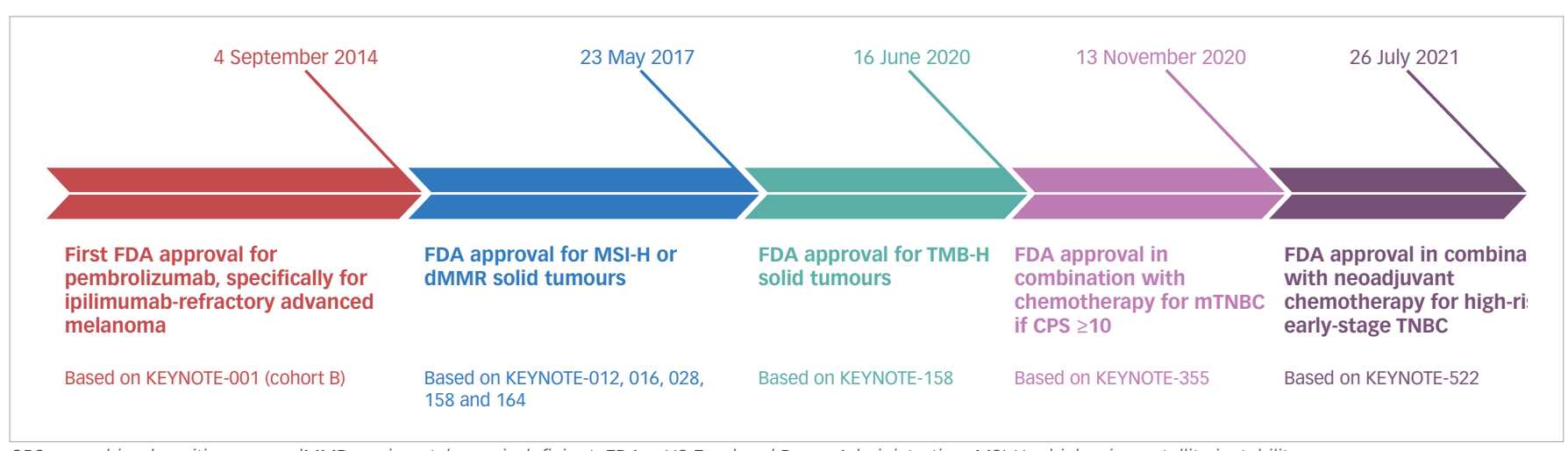

CPS = combined positive score; $d M M R=$ mismatch repair deficient; $F D A=$ US Food and Drugs Administration; $M S I-H$ = high microsatellite instability;

ITNBC = metastatic triple-negative breast cancer; $T M B-H=$ high tumour mutational burden .

in the control arm, mOS was equivalent between the ITT groups. However, mOS improved for the pembrolizumab arm as the CPS score increased, though the difference was statistically insignificant (ITT net -0.9 months, CPS $\geq 1$ net +0.5 months, CPS $\geq 10$ net +1.1 months). A post hoc exploratory analysis for patients with a CPS $\geq 20(n=6)$ was later performed, which found that mos was 14.9 months versus 12.5 months (hazard ratio (HR) 0.58; 95\% confidence interval (Cl) 0.38-0.88) in the control group. The main takeaway from KEYNOTE-119 was that pembrolizumab did not improve outcomes compared with singleagent chemotherapy. However, whether pembrolizumab monotherapy could be deemed a suitable alternative to chemotherapy in treatmentrefractory $\mathrm{MTNBC}$ necessitates further research, as this study was not designed as a non-inferiority trial.

\section{Pembrolizumab combination therapy TOPACIO: pembrolizumab + niraparib}

Niraparib inhibits poly(adenosine diphosphate ribose) polymerase (PARP), an enzyme important for repairing double-stranded DNA breaks, and is efficacious when used against tumours deficient in DNA repair enzymes, specifically those with mutations of either breast cancer gene type 1 (BRCA1) or type 2 (BRCA2). TOPACIO was a single-arm phase II trial that combined niraparib with pembrolizumab in patients with advanced TNBC, regardless of their BRCA status, with the primary outcome of ORR. ${ }^{53}$ Of the 47 patients who had available efficacy data, 15 (32\%) had tumour-mutated BRCA, and 28 (60\%) were found to be PD-L1 positive, though certain patients were untested among the total group. Regarding outcomes, the overall ORR was 21\%. Among PD-L1-positive patients, the ORR was 32\% (versus 8\% in PD-L1 negative), whereas among BRCAmutated patients, the ORR was $47 \%$ (versus $11 \%$ in BRCA wild-type). Overall, the combination therapy appeared to be auspicious, but given the small sample size, limited conclusions could be drawn.

\section{Pembrolizumab + capecitabine}

Capecitabine is a pro-drug of 5 -fluorouracil that works by inhibiting thymidylate synthase. This prevents the production of thymidine, which is essential for DNA synthesis. A phase II trial assessed the combination of pembrolizumab with capecitabine in patients with non-HER2expressing breast cancers. ${ }^{54}$ Of the 30 patients enrolled, 16 had mTNBC. In all patients, the ORR was $14 \%$ (13\% for TNBC), mPFS was 4.0 months (4.0 months for TNBC) and mOS was 15.4 months (15.3 months for TNBC). The trial was adequately powered but failed to demonstrate a meaningful improvement in PFS compared with historic controls. PD-L1 positivity was observed in $40 \%$ of all patients, but calculated at $60 \%$ in the TNBC subgroup.

\section{ENHANCE: pembrolizumab + eribulin}

Eribulin works primarily as a microtubule inhibitor and is typically reserved for treating metastatic breast cancer in patients previously treated with taxane and anthracycline therapies. ENHANCE was a singlearm, phase $\mathrm{Ib}$ trial that enrolled 107 patients with mTNBC with $\leq 2$ prior lines of systemic therapy regimens, and tested the combination of pembrolizumab and eribulin. ${ }^{55}$ The phase Ib run-in with six patients found the recommended phase II doses to be eribulin $1.4 \mathrm{mg} / \mathrm{m}^{2}$ on Days 1 and 8 of the 21-day cycle and pembrolizumab $200 \mathrm{mg}$ on Day 1. For phase II of the trial, the resulting ORR was $23.4 \%$ with an MPFS of 4.1 months and mOS of 16.1 months. Patients were stratified based on their current line of therapy and PD-L1 positivity. While there was a trend towards improved outcomes in those who were PD-L1 positive and on first-line therapy, the study was too small to make any definitive claims.

\section{KEYNOTE-355}

KEYNOTE-355 was a large phase III, double-blinded, international, placebo-controlled trial in which 847 patients with advanced TNBC were assigned 2:1 to receive either pembrolizumab or placebo in addition to conventional frontline chemotherapy. ${ }^{56} \mathrm{Physician}$ 's choice for conventional chemotherapy included paclitaxel $\left(90 \mathrm{mg} / \mathrm{m}^{2}\right.$ on Days 1,8 and 15 , every 28 days), nab-paclitaxel (100 mg/m² on Days 1,8 and 15, every 28 days) or combination gemcitabine/carboplatin (gemcitabine $1,000 \mathrm{mg} / \mathrm{m}^{2}$ plus carboplatin with an area under the curve of 2 on Days 1 and 8, every 21 days). Pembrolizumab/placebo was given at a standard dose of 200 mg intravenous (IV) every 21 days. The primary outcomes were initially designed to stratify overall survival and PFS between the ITT population and patients with CPS $\geq 1$, but following newer biomarker outcome data, the investigators further subcategorized patients with a CPS $\geq 10$, as this cohort was likely to show improved outcomes. ${ }^{57}$ During the release of the second interim results, analysis of overall survival was still ongoing but the final assessment of PFS was completed with a median followup of roughly 26 months for each arm. A significant increase in MPFS was observed in the CPS $\geq 10$ experimental arm at 9.7 months versus 5.6 months ( $p=0.0012$ ) for the placebo arm. However, for the CPS $\geq 1$ group, mPFS was only 7.6 months with the addition of pembrolizumab versus 5.6 months without, which did not meet statistical significance. Due to the hierarchical multiplicity strategy that was implemented, statistical significance was not formally tested in the ITT group, but mPFS was found to be 7.5 months versus 5.6 months, respectively.

Secondary outcomes were later presented as an abstract at the 2020 Virtual San Antonio Breast Cancer Symposium (SABCS). ${ }^{58}$ When analysing the ITT cohort, the ORR was $41.0 \%$ (versus $35.9 \%$ for placebo), the 
disease control rate (DCR) was 56.0\% (versus 51.6\%), and the median duration of response (mDOR) was 10.1 months (versus 6.4 months). All three outcomes further improved with increased PD-L1 expression, as seen in the CPS $\geq 10$ group, with an ORR of $53.2 \%$ (versus $39.8 \%$ for placebo), DCR of $65.0 \%$ (versus $54.5 \%$ ) and mDOR of 19.3 months (versus 7.3 months). The abstract also included individual PFS data for each chemotherapy agent used, though the trial was underpowered for comparing efficacy among the individual regimens. Chemotherapy regimens ranked from highest to lowest MPFS in the ITT population were: paclitaxel (8.0 months versus 3.8 months for the control, $\mathrm{HR} 0.57,95 \% \mathrm{Cl}$ 0.35-0.93), nab-paclitaxel (7.5 versus 5.4 months, HR 0.69, 95\% Cl 0.510.93 ) and gemcitabine/carboplatin (7.4 versus 7.4 months, HR $0.93,95 \%$ $\mathrm{Cl}$ 0.74-1.16). This pattern remained the same for the CPS $\geq 1$ and CPS $\geq 10$ groups, even as the gap in mPFS widened between the experimental and control arms as CPS increased.

In summary, KEYNOTE-355 showed that there was a statistically meaningful benefit in PFS for patients with a CPS $\geq 10$. Given these findings, the FDA issued an accelerated approval of pembrolizumab plus chemotherapy for use as first-line therapy in patients with PD-L1-postitive (CPS $\geq 10$ ) mTNBC..$^{18}$ In July 2021, the US FDA granted regular approval to pembrolizumab plus chemotherapy based on the final survival analysis, which demonstrated improved median survival (23 verses 16.1 months for the control (HR 0.73, 95\% Cl 0.55 - 0.93). ${ }^{59}$ The National Comprehensive Cancer Network (NCCN) has also made a category 1 recommendation regarding the combination of pembrolizumab with the chemotherapy options listed above in patients with tumours that have a CPS $\geq 10$ based on the Dako $22 \mathrm{C} 3 \mathrm{IHC}$ assay. ${ }^{60}$

\section{Discussion}

There has been a wave of new immunotherapy trials involving mTNBC in recent years. The individual designs and results of these trials are conveniently summarized for easy comparison in Table 2.29,3,49-52,54-56,58,59

When reviewing the summarized results of monotherapy trials, it becomes clear that outcomes are consistently inferior to combination regimens, limiting their utility as stand-alone treatments, in contrast to other cancer types. This is true even when evaluating alternative immunotherapy agents, including atezolizumab and avelumab. The most notable trial regarding $\mathrm{ICI}$ monotherapy is KEYNOTE-119. Given that this direct comparison study of immunotherapy versus chemotherapy omitted platinum and taxane regimens (some of the most active agents in TNBC), it is hard to argue for the use of $\mathrm{ICI}$ monotherapy in place of conventional chemotherapy until those options have been explored first. The place where $\mathrm{ICl}$ monotherapy may eventually play a role, as seen in the post hoc analysis of KEYNOTE-119, is in MTNBC that expresses PD-L1 at exceptionally high levels, though this represents lower quality data that needs further vetting. ${ }^{61}$ Similar to non-small cell lung cancer (NSCLC), we may find that beyond a certain cut-off (e.g. CPS $\geq 50$ ), ICI monotherapy might suffice in comparison with combination therapy, with the understanding that this would represent a slim minority of the total mTNBC population. Monotherapy could also be considered in patients with MSI-H or TMB-H disease, though again this occurs infrequently.

For combination therapy, results have been more promising, though equally complex. One of the earliest phase III breast cancer trials to implement ICI therapy for the treatment of MTNBC was IMpassion130, which was a randomized placebo-controlled trial $(n=902)$ that enrolled patients with untreated metastatic or locally advanced TNBC who received nab-paclitaxel +/- atezolizumab. ${ }^{62,63}$ The trial demonstrated a numerical but statistically insignificant increase in mOS in both the ITT and PD-L1 positive (defined as SP142 immune cells $\geq 1 \%$ ) cohorts with the addition of atezolizumab (21.0 months versus 18.7 months and 25.4 months versus 17.9 months, respectively). However, compared with nab-paclitaxel alone, adding atezolizumab significantly improved mPFS both in the ITT group (7.2 months versus 5.5 months; $p=0.002$ ) and in the PD-L1-positive subgroup (7.5 months versus 5.3 months; $p<0.001$ ). Following the success of IMpassion130, atezolizumab/nab-paclitaxel was streamlined to first-line therapy for the treatment of MTNBC, and implemented into the NCCN and ESMO guidelines, specifically for use in patients with PD-L1-positive MTNBC. ${ }^{60,64}$

Interestingly, IMpassion131 evaluated paclitaxel +/- atezolizumab as first-line therapy in patients with PD-L1-positive MTNBC. However, it did not demonstrate an improvement in PFS between the two groups. ${ }^{65}$ In September 2020, the FDA issued an efficacy and safety alert based on the trial results. ${ }^{66}$ Approximately one year later, on August 27, 2021, the manufacturer of atezolizumab (Genentech) voluntarily withdrew the accelerated approval indication for atezolizumab plus nab-paclitaxel in mTNBC. Continued approval of atezolizumab in the mTNBC setting was contingent upon the final IMpassion131 study results, of which were published in early August 2021 and showed that the study failed to meet its endpoint. ${ }^{67}$

When we compare both IMpassion studies to KEYNOTE-355, we find the designs were quite similar. Patient populations and characteristics were alike among these studies, including the percentage of patients who had been previously exposed to taxanes in the neoadjuvant or adjuvant settings for non-metastatic disease. ORR was lower in KEYNOTE-355, both for the ITT (41.0\% versus 56.0\% and 54.0\%) and PD-L1-positive (45.2\% versus $58.9 \%$ and $63.0 \%$ ) groups compared with the IMpassion 130 and IMpassion131, respectively. However, with an ITT MPFS of 7.5 months (versus 7.2 and 5.6 months in IMpassion130 and IMpassion131, respectively) and a PD-L1-positive subgroup MPFS of 7.6 months (versus 7.5 and 5.7 months), it becomes clear that, as with most ICI therapies, duration of response plays a stronger role than initial response rates. This brings up an ongoing question regarding what factors impair treatment response. Data regarding immune-related adverse events (irAEs) were limited in the IMpassion studies, but for KEYNOTE-355, grade 3 irAEs were reported in $5 \%$ of the pembrolizumab arm versus $0.0 \%$ in the placebo arm, with rash being the most common event (2.0\% total). For all grades of irAEs, $26.0 \%$ were reported for the experimental arm versus $6.0 \%$ in the placebo arm, most commonly thyroid disease (20.0\% versus $4.0 \%$ ).

One of the initial concerns regarding the use of ICI therapy in breast cancer revolved around its intrinsically low expression of PD-L1. Surrounding immune cells make up the majority of positive PD-L1-expressing cells when using both PD-L1 assays, whereas less than $25.0 \%$ of the malignant breast cells themselves express PD-L1 on their surface. ${ }^{42}$ Contrast this with more immunosensitive tumours, such as NSCLC, where surface PDL1 expression on malignant cells and immune cells is near equal. ${ }^{68-70}$

\section{Conclusion and future directions}

There is mounting evidence regarding the benefit of immunotherapy in breast cancer. A clear clinical benefit is observed when immunotherapy is combined with conventional chemotherapy as first-line treatment for mTNBC that expresses PD-L1, particularly cancers with higher expression, such as those with a CPS $\geq 10$.

Future studies involving ICls in breast cancer include those that combine ICIs with various treatments, such as radiation therapy, PARP 
Table 2: Comparison of the various immunotherapy trials performed to date for metastatic triple-negative breast cancer involving pembrolizumab

\begin{tabular}{|c|c|c|c|c|c|c|c|c|}
\hline Therapy & Phase & $\begin{array}{l}\text { Line of } \\
\text { therapy }\end{array}$ & Population & $\begin{array}{l}\text { PD-L1 } \\
\text { positivity (\%) }\end{array}$ & $n$ & $\begin{array}{l}\text { Median OS } \\
\text { (months) }\end{array}$ & $\begin{array}{l}\text { Median PFS } \\
\text { (months) }\end{array}$ & ORR (\%) \\
\hline 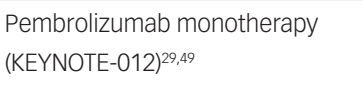 & Ib & All & PD-L1+ only & 100 & 27 & 11.2 & 1.9 & 18.5 \\
\hline $\begin{array}{l}\text { Pembrolizumab + eribulin } \\
\text { (ENHANCE) }^{55}\end{array}$ & $\mathrm{Ib} / \mathrm{II}$ & $1-3$ & ITT & 49.6 & 107 & 16.1 & 4.1 & 23.4 \\
\hline $\begin{array}{l}\text { Pembrolizumab monotherapy } \\
\text { (TAPUR) }^{33}\end{array}$ & $\|$ & $\geq 3$ & ITT & $\mathrm{N} / \mathrm{A}$ & 28 & 7.0 & 2.4 & 21.0 \\
\hline Pembrolizumab + capecitabine ${ }^{54}$ & $\|$ & All & ITT & $\begin{array}{l}\text { Overall: } 40 \\
\text { TNBC: } 60\end{array}$ & $\begin{array}{l}30 \\
(16 \mathrm{TNBC})\end{array}$ & $\begin{array}{l}\text { Overall: } 15.4 \\
\text { TNBC: } 15.3\end{array}$ & $\begin{array}{l}\text { Overall: } 4.0 \\
\text { TNBC: } 4.0\end{array}$ & $\begin{array}{l}\text { Overall: } 14 \\
\text { TNBC: } 13\end{array}$ \\
\hline $\begin{array}{l}\text { Pembrolizumab monotherapy } \\
\text { (KEYNOTE-086 Cohort A) })^{50}\end{array}$ & $\|$ & $\geq 2$ & ITT & 61.8 & 170 & 9.0 & 2.0 & $\begin{array}{l}\text { Overall: } 5.3 \\
\text { PD-L1+: } 5.7 \\
\text { PD-L1-: } 4.7\end{array}$ \\
\hline $\begin{array}{l}\text { Pembrolizumab monotherapy } \\
\text { (KEYNOTE-086 Cohort B) })^{51}\end{array}$ & $\|$ & 1 & PD-L1+ only & 86.9 & 84 & 18.0 & 2.1 & 21.4 \\
\hline $\begin{array}{l}\text { Pembrolizumab + niraparib } \\
\text { (TOPACIO) }^{53}\end{array}$ & $\|$ & $1-3$ & ITT & 68.3 & 47 & N/A & 2.3 & $\begin{array}{l}\text { Overall: } 21 \\
\text { PD-L1+: } 32 \\
\text { PD-L1-:8 }\end{array}$ \\
\hline $\begin{array}{l}\text { Pembrolizumab monotherapy vs } \\
\text { chemotherapy } \\
\text { (KEYNOTE-119) }^{52}\end{array}$ & III & $2-3$ & ITT & 65.1 & 622 & $\begin{array}{l}\text { ITT: } 9.9 \text { versus } 10.8 \\
\text { CPS } \geq 1: 10.7 \text { versus } \\
10.2 \\
\text { CPS } \geq 10: 12.7 \\
\text { versus } 11.6 \\
\text { CPS } \geq 20: 14.9 \\
\text { versus } 12.5\end{array}$ & $\begin{array}{l}\text { ITT: } 2.1 \\
\text { versus } 3.3 \\
C P S \geq 1: 2.1 \text { versus } \\
3.1 \\
\text { CPS } \geq 10: 2.1 \text { versus } \\
3.4\end{array}$ & $\begin{array}{l}\text { ITT: } 9.6 \text { versus } 10.6 \\
\text { CPS } \geq 1: 12.3 \text { versus } \\
9.4 \\
\text { CPS } \geq 10: 17.7 \\
\text { versus } 9.2\end{array}$ \\
\hline $\begin{array}{l}\text { Pembrolizumab + chemotherapy } \\
\text { (KEYNOTE-355) }^{56,58,59}\end{array}$ & III & 1 & ITT & 75.6 & 847 & $\begin{array}{l}\text { CPS } \geq 10: 23 \\
\text { months versus } 16.1 \\
\text { months }\end{array}$ & $\begin{array}{l}\text { ITT: } 7.5 \text { versus } 5.6 \\
\text { CPS } \geq 1: 7.6 \text { versus } \\
5.6 \\
\text { CPS } \geq 10: 9.7 \text { versus } \\
5.6\end{array}$ & $\begin{array}{l}\text { ITT: } 41.0 \\
\text { versus } 35.9 \\
\text { CPS } \geq 1: 45.2 \text { versus } \\
37.9 \\
\text { CPS } \geq 10: 53.2 \\
\text { versus } 35.9\end{array}$ \\
\hline
\end{tabular}

+ = positive; - = negative; CPS = combined positive score; ITT = intention-to-treat; ORR = objective response rate; OS = overall survival; PD-L1 = programmed death-ligand 1; PFS = progression-free survival; TNBC = triple-negative breast cancer.

inhibitors, HER2-directed therapy, cyclin-dependent kinase (CDK) 4/6 inhibitors, mitogen-activated protein kinase kinase (MEK) inhibitors, epigenetic therapy, and indoleamine-pyrrole 2,3-dioxygenase (IDO) inhibitors. ${ }^{71}$ The number of novel immune checkpoint agents is also on the rise, with many already entering phase $1 / I I$ trials, usually in the form of combination therapy. ${ }^{72,73}$ These include drugs that target inhibitory immune checkpoints (LAG3, TIM-3, TIGIT, VISTA, B7-H3) along with co-stimulants (OX-40, GITR, CD27, CD137). Some are even engineered as viral vectors (e.g. adenovirus vector-mediated OX40 ligand gene transfer) or bispecific antibodies (e.g. MGD013, PD-1 and LAG3) to further improve efficacy. ${ }^{74}$ Given this explosion of new-wave pharmaceuticals being tested, the standard of care for MTNBC will continue to evolve in years to come with the hope of improving clinical outcomes in patients with breast cancer. $\mathrm{u}$
1. Bauer $\mathrm{KR}$, Brown $\mathrm{M}$, Cress RD, et al. Descriptive analysis of estrogen receptor (ER)-negative, progesterone receptor (PR)-negative, and HER2-negative invasive breast cancer, the so-called triple-negative phenotype: a population-based study from the California cancer Regitry: Cancer 2007:109:1721-8.

2. Early Breast Cancer Trialists' Collaborative Group. Systemic Early Breast Cancer Trialists Collaborative Group. Systemic treatment of early breast cancer by hormonal, cytotoxic, or immune therapy. 133 randomised trials involving 31,000
recurrences and 24,000 deaths among 75,000 women. Lancet. 1992:339:1-15.

3. Steward $L$, Conant $L, G a o F$, Margenthaler JA. Predictive factors and patterns of recurrence in patients with triple negative breast cancer. Ann Surg Oncol. 2014;21:2165-71.

4. Hugh J, Hanson J, Cheang MC, et al. Breast cancer subtypes and response to docetaxel in node-positive breast cancer: use of an immunohistochemical definition in the BCIRG 001 trial. J Clin
Oncol. 2009;27:1168-76.

5. Li CH, Karantza V, Aktan G, Lala M. Current treatment landscape for patients with locally recurrent inoperable or metastatic triple-negative breast cancer a systematic literature review. Breast Cancer Res. 2019;21:143.

6. Leo CP, Leo C, SzuCS TD. Breast cancer drug approvals by the US FDA from 1949 to 2018 . Nat Rev Drug Discov 2020;19:11. Prowell TM, Pazdur R. Pathological complete response and accelerated drug approval in early breast cancer. N Eng/ I Med. 2012;366:2438-4

8. Okazaki T, Honjo T. PD-1 and PD-1 ligands: from discovery to clinical application. Int Immunol. 2007;19:813-24.

. Zang X, Allison JP. The B7 family and cancer therapy: costimulation and coinhibition. Clin Cancer Res. 2007;13:5271-9.

10. Latchman Y, Wood CR, Chernova T, et al. PD-L2 is a second ligand for PD-1 and inhibits T cell activation. Nat Immunol.
2001;2:261-8.

1. Nishimura H, Agata Y, Kawasaki A, et al. Developmentally regulated expression of the PD-1 protein on the surface of double-negative (CD4-CD8-) thymocytes. Int Immunol 1996:8:773-80.

12. Dong $\mathrm{H}$, Strome SE, Salomao DR, et al. Tumor-associated B7-H1 promotes T-cell apoptosis: a potential mechanism of immune evasion. Nat Med. 2002;8:793-800.

13. Disis ML. Immune regulation of cancer. I Clin Oncol. 2010;28:4531-8

14. Rozali EN, Hato SV, Robinson BW, et al. Programmed death ligand 2 in cancer-induced immune suppression. Clin Dev Immunol. 2012;2012:656340.

15. Leach DR, Krummel MF, Allison JP. Enhancement of antitumo immunity by CTLA-4 blockade. Science. 1996;271:1734-6. 16. Iwai Y, Ishida M, Tanaka Y, et al. Involvement of PD-L1 on tumor 
cells in the escape from host immune system and tumor immunotherapy by PD-L1 blockade. Proc Natl Acad Sci U S A 2002;99:12293-7.

17. Patnaik A, Kang SP, Rasco D, et al. Phase I study of pembrolizumab (MK-3475; anti-PD-1 monoclonal antibody) in patients with advanced solid tumors. Clin Cancer Res. 2015;21:4286-93.

18. US Food and Drug Administration. KEYTRUDA (pembrolizumab) Prescribing Information. 2021. Available at: www.merck.com/ product/usa/pi_circulars/k/keytruda/keytruda_pi.pdf (accessed 13 August 2021)

19. Hamid O, Robert C, Daud A, et al. Five-year survival outcomes for patients with advanced melanoma treated with pembrolizumab in KEYNOTE-001. Ann Oncol. 2019;30(4):582-8.

20. Vaddepally RK, Kharel P, Pandey R, et al. Review of indications of FDA-approved immune checkpoint inhibitors per NCCN guidelines with the level of evidence. Cancers (Basel). 2020;12:738.

21. Marabelle A, Le DT, Ascierto PA, et al. Efficacy of pembrolizumab in patients with noncolorectal high microsatellite instability/ in patients with noncolorectal high microsatellite instability/
mismatch repair-deficient cancer. results from the phase II KEYNOTE-158 study. J Clin Oncol. 2020:38:1-10.

22. Marabelle A, Fakih M, Lopez J, et al. Association of tumour mutational burden with outcomes in patients with advanced solid tumours treated with pembrolizumab: prospective biomarker analysis of the multicohort, open-label, phase 2 KEYNOTE-158 study. Lancet Oncol. 2020; 21:1353-65.

23. Schmid P, Cortes J, Pusztai L, et al. KEYNOTE-522 Investigators. Pembrolizumab for Early Triple-Negative Breast Cancer. N Eng/ Med. 2020;382:810-21

24. Gubin MM, Artyomov MN, Mardis ER, Schreiber RD. Tumor neoantigens: building a framework for personalized cancer immunotherapy. J Clin Invest. 2015;125:3413-21.

25. Pietrantonio F, Miceli R, Raimondi A, et al. Individual patient data meta-analysis of the value of microsatellite instability as a biomarker in gastric cancer. J Clin Oncol. 2019;37:3392-400.

26. Fusco MJ, West HJ, Walko CM. Tumor mutation burden and cancer treatment IAMA Oncol 2020:7:316.

27. Le DT, Uram JN, Wang H, et al. PD-1 blockade in tumors with mismatch-repair deficiency. N Eng/ J Med. 2015;372:2509-20

28. Le DT, Kim TW, Custem EV, et al Phase II Open-Label Study of Pembrolizumab in Treatment-Refractory, Microsatellite Instability-High/Mismatch Repair-Deficient Metastatic Colorectal Cancer: KEYNOTE-164. J Clin Oncol. 2020;38:11-19

29. Nanda R, Chow LQ, Dees EC, et al. Pembrolizumab in patients with advanced triple-negative breast cancer: Phase Ib KEYNOTE-012 study. J Clin Oncol. 2016;34:2460-7.

30. Alley EW, Lopez J, Santoro A et al Clinical safety and activity of pembrolizumab in patients with malignant pleural mesothelioma (KEYNOTE-028): preliminary results from a non-randomised, open-label, phase $1 \mathrm{~b}$ trial. Lancet Oncol 2017:20:5:623-30

31. Sivapiragasam A, Ashok Kumar P, Sokol ES, et al. Predictive biomarkers for immune checkpoint inhibitors in metastatic breast cancer. Cancer Med. 2021;10:53-61.

32. Barroso-Sousa R, Jain $E$, Cohen $O$, et al. Prevalence and mutational determinants of high tumor mutation burden in breast cancer. Ann Oncol. 2020;31:387-94.

33. Alva AS, Mangat PK, Garrett-Mayer E, et al. Pembrolizumab in patients with metastatic breast cancer with high tumor mutational burden: results from the targeted agent and profiling utilization registry (TAPUR) study I Clin Oncol. 2021:JCO2002923.

34. Guo H, Ding Q, Gong $Y$, et al. Comparison of three scoring methods using the FDA-approved 22C3 immunohistochemistry assay to evaluate PD-L1 expression in breast cancer and their association with clinicopathologic factors. Breast cancer Res. 2020:22:69

35. Noske A, Ammann JU, Wagner DC, et al. A multicentre analytical comparison study of inter-reader and inter-assay agreement of four programmed death-ligand 1 immunohistochemistry assays for scoring in triple-negative breast cancer. Histopathology. 2021;78:567-77.

36. Li Y, Vennapusa B, Chang $\mathrm{CW}$, et al. Prevalence study of PD-L1 SP142 assay in metastatic triple-negative breast cancer. App Immunohistochem Mol Morphol. 2020;29:258-64.

37. Roach C, Zhang N, Corigliano $\mathrm{E}$, et al. Development of a companion diagnostic PD-L1 immunohistochemistry assay for pembrolizumab therapy in non-small-cell lung cancer. Appl Immunohistochem Mol Morphol. 2016;24:392-7.

38. Kulangara $\mathrm{K}$, Hanks DA, Waldroup $\mathrm{S}$, et al. Development of the combined positive score (CPS) for the evaluation of PD-L1 in solid tumors with the immunohistochemistry assay PD-L1 IHC 22C3 pharmDx. J Clin Oncol. 2017;35(Suppl. 15):e14589.

39. Huang $X$, Ding $Q$, Guo $H$, et al. Comparison of three FDAapproved diagnostic immunohistochemistry assays of PD-L1 in triple-negative breast carcinoma. Hum Pathol. 2020;108:42-50

40. Ghebeh H, Mohammed S, Al-Omair A, et al. The B7-H1 (PD-L1) lymphocyte-inhibitory molecule is expressed in breast cancer patients with infiltrating ductal carcinoma: correlation with important high-risk prognostic factors. Neoplasia. 2006;8:190-8.

41. Mittendorf EA, Philips AV, Meric-Bernstam F, et al. PD-L1 expression in triple-negative breast cancer. Cancer Immunol Res. 2014;2:361-70.

42. Beckers RK, Selinger $\mathrm{Cl}$, Vilain $\mathrm{R}$, et al. Programmed death ligand 1 expression in triple-negative breast cancer is associated with tumour-infiltrating lymphocytes and improved outcome. Histopathology. 2016;69:25-34.

43. Rozenblit M, Huang R, Danziger N, et al. Comparison of PD-L1 protein expression between primary tumors and metastatic lesions in triple negative breast cancers. I Immunother Cancer 2020;8:e001558.

44. Duchnowska R, Pęksa R, Radecka B, et al. Immune response in breast cancer brain metastases and their microenvironment: the role of the PD-1/PD-L axis. Breast Cancer Res. 2016;18:43.

45. Peng W, Chen JQ, Liu C, et al. Loss of PTEN promotes resistance to T cell-mediated immunotherapy. Cancer Discov. 2016;6:202-16

46. Garrido-Castro AC, Lin NU, Polyak K. Insights into molecular classifications of triple-negative breast cancer: improving patient selection for treatment. Cancer Discov. 2019:9:176-98.

47. Zhang P, Su DM, Liang M, Fu J. Chemopreventive agents induce programmed death-1-ligand 1 (PD-L1) surface expression in breast cancer cells and promote PD-L1-mediated T Cel apoptosis. Mol Immunol. 2008;45:1470-6.

48. Samanta D, Park Y, Ni X, et al. Chemotherapy induces enrichment of $\mathrm{CD} 47+/ \mathrm{CD} 73+/ P D L 1+$ immune evasive triple-negative breast cancer cells. Proc Natl Acad Sci U S A 2018;115:E1239-48.

49. Nanda R, Specht J, Dees C, et al. KEYNOTE-012: Long-lasting responses in a phase $\mathrm{Ib}$ study of pembrolizumab for metastatic triple-negative breast cancer (mTNBC). Presented at: 2016 San Antonio Breast Cancer Symposium, San Antonio, Texas, 6-10 December 2016. Abstract P6-10-03.

50. Adams S, Schmid P, Rugo HS, et al. Pembrolizumab monotherapy for previously treated metastatic triple-negative breast cancer: cohort A of the phase II KEYNOTE-086 study. Ann Oncol. 2019;30:397-404.

51. Adams $S$, Loi $S$, Toppmeyer $D$, et al. Pembrolizumab monotherapy for previously untreated, PD-L1-positive metastatic triple-negative breast cancer: cohort $\mathrm{B}$ of the phase II KEYNOTE-086 study. Ann Oncol. 2019;30:405-11.

52. Cortés J, Lipatov O, Im S, et al. KEYNOTE-119: Phase 3 study of pembrolizumab (pembro) versus single-agent chemotherapy (chemo) for metastatic triple-negative breast cancer (MTNBC) Presented at: ESMO 2019 Congress, Barcelona, Spain, 28 September 2019. Abstract\#1103.

53. Vinayak S, Tolaney SM, Schwartzberg L, et al. Open-label clinical trial of niraparib combined with pembrolizumab for treatment of advanced or metastatic triple-negative breast cancer. JAMA Oncol. 2019:5:1132-40

54. Shah AN, Flaum L, Helenowski I, et al. Phase II study of pembrolizumab and capecitabine for triple negative and hormone receptor-positive, HER2-negative endocrinerefractory metastatic breast cancer. J Immunother Cancer. refractory metas

55. Tolaney SM, Kalinsky K, Kaklamani VG, et al. A phase Ib/II study of eribulin (ERI) plus pembrolizumab (PEMBRO) in metastatic triple-negative breast cancer (MTNBC) (ENHANCE 1). J Clin Oncol. 2020;38:1015.

56. Cortes J, Cescon DW, Rugo HS, et al. Pembrolizumab plus chemotherapy versus placebo plus chemotherapy for previously untreated locally recurrent inoperable or metastatic triple-negative breast cancer (KEYNOTE-355): a randomised, placebo-controlled, double-blind, phase 3 clinical trial. Lancet. 2020;396:1817-28.

57. Emens LA, Cruz C, Eder JP, et al. Long-term clinical outcomes and biomarker analyses of atezolizumab therapy for patients with metastatic triple-negative breast cancer: a phase 1 study. IAMA OnCOL 2019:5:74-82.

58. Rugo HS, Schmid P, Cescon DW, et al. Additional efficacy endpoints from the phase 3 KEYNOTE-355 study of pembrolizumab plus chemotherapy vs placebo plus chemotherapy as first-line therapy for locally recurren inoperable or metastatic triple-negative breast cancer. Presented at: SABCS 2020, Virtual, 10 December 2020. Abstract \#GS3-01.

59. Rugo HS, Cortés J, Cescon DW, et al. KEYNOTE-355: Final results from a randomized, double-blind phase 3 study of first-line pembrolizumab + chemotherapy vs placebo + chemotherapy for metastatic TNBC. Presented at: ESMO Congress 2021. Abstract \#LBA16.

60. Gradishar WJ, Moran MS, Abraham J, et al. National Comprehensive Cancer Network. Breast Cancer (version Available at: www.nccn.org/professionals/ physician_gls/pdf/breast.pdf (accessed 23 August 2021).

61. Amir E, Cescon DW. Pembrolizumab monotherapy in metastatic triple-negative breast cancer. Lancet Oncol. 2021:S14702045(21)00019-X

62. Schmid P, Adams S, Rugo HS, et al. Atezolizumab and nabpaclitaxel in advanced triple-negative breast cancer. $N$ Eng/ J Med. 2018;379:2108-21.

63. Emens LA, Adams S, Barrios CH, et al. IMpassion130: Final OS analysis from the pivotal phase III study of atezolizumab + nabpaclitaxel vs placebo + nab-paclitaxel in previously untreated locally advanced or metastatic triple-negative breast cancer. Presented at: ESMO Virtual Congress, Virtual, 19 September 2020. Abstract \#lBA16.

64. Cardoso F, Paluch-Shimon S, Senkus E, et al. 5th ESO-ESMO international consensus guidelines for advanced breast cancer (ABC 5). Ann Oncol. 2020:31:1623-49.

65. Miles DW, Gligorov J, André F, et al. Primary results from IMpassion131, a double-blind placebo-controlled randomised phase III trial of first-line paclitaxel $(\mathrm{PAC}) \pm$ atezolizumab (atezo) for unresectable locally advanced/metastatic triple-negative breast cancer (mTNBC). Presented at: ESMO 2020 Congress, Virtual, 19 September 2020. Abstract \#LBA15.

66. US Food and Drug Administration. FDA alerts health care professionals and oncology clinical investigators about efficacy and potential safety concerns with atezolizumab in combination with paclitaxel for treatment of breast cancer. 2020. Available at: https://www.fda.gov/drugs/drug-safety-andavailability/fda-alerts-health-care-professionals-and-oncologyclinical-investigators-about-efficacy-and (accessed 23 August 2021).

67. Miles D, Gligorov J, André F, et al. Primary results from IMpassion131, a double-blind, placebo-controlled, randomised phase III trial of first-line paclitaxel with or without atezolizumab for unresectable locally advanced/metastatic triple-negative breast cancer. Ann Oncol. 2021;32(8):994-1004 doi:10.1016/j.annonc.2021.05.801

68. Brahmer J, Reckamp KL, Baas P, et al. Nivolumab versus docetaxel in advanced squamous-cell non-small-cell lung cancer. N Eng/ J Med. 2015;373:123-35.

69. Borghaei H, Paz-Ares L, Horn L, et al. Nivolumab versus docetaxel in advanced nonsquamous non-small-cell lung cancer. N Eng/ J Med. 2015;373:1627-39.

70. Yu H, Boyle TA, Zhou C, et al. PD-L1 expression in lung cancer. J Thorac Oncol. 2016;11:964-75.

71. Emens LA. Breast cancer immunotherapy: facts and hopes. Clin Cancer Res. 2018;24:511-20.

72. Qin S, Xu L, Yi M, et al. Novel immune checkpoint targets: moving beyond PD-1 and CTLA-4. Mol Cancer. 2019;18:155.

73. Sanmamed MF, Pastor F, Rodriguez A, et al. Agonists of co-stimulation in cancer immunotherapy directed against CD137, OX40, GITR, CD27, CD28, and ICOS. Semin Oncol. 2015;42:640-55

74. Andarini S, Kikuchi T, Nukiwa M, et al. Adenovirus vectormediated in vivo gene transfer of OX40 ligand to tumor cells enhances antitumor immunity of tumor-bearing hosts. Cancer Res. 2004;64:3281-7. 